\title{
Incremental structure building of preverbal PPs in Dutch
}

\author{
Cas W. Coopmans \& Gert-Jan Schoenmakers \\ Max Planck Institute for Psycholinguistics $\mid$ Radboud University
}

Incremental comprehension of head-final constructions can reveal structural attachment preferences for ambiguous phrases. This study investigates how temporarily ambiguous PPs are processed in Dutch verb-final constructions. In De aannemer heeft op het dakterras bespaard/gewerkt 'The contractor has on the roof terrace saved/worked', the PP is locally ambiguous between attachment as argument and as adjunct. This ambiguity is resolved by the sentence-final verb. In a self-paced reading task, we manipulated the argument/adjunct status of the PP, and its position relative to the verb. While we found no reading-time differences between argument and adjunct PPs, we did find that transitive verbs, for which the PP is an argument, were read more slowly than intransitive verbs, for which the PP is an adjunct. We suggest that Dutch parsers have a preference for adjunct attachment of preverbal PPs, and discuss our findings in terms of incremental parsing models that aim to minimize costly reanalysis.

Keywords: PP attachment, arguments and adjuncts, head-final constructions, self-paced reading, parsing

\section{Introduction}

Prepositional phrases (PPs) can be arguments or adjuncts, depending on the selectional properties of the verbal head. As arguments are assigned a thematic role by this verbal head, their meaning depends on their relationship with the selecting verb (see Schütze 1995). Adjuncts predicate a separate property of the verbal head, and their semantic contribution is relatively independent of the verb's meaning. Consider the sentence in (1), which is ambiguous between a reading in which the man waited on the boat, and a reading in which he waited (somewhere) for the boat to arrive. That is, the PP op de boot 'on the boat' is either an adjunct with an independent locative interpretation, or an argument, lexically specified by the verb waiting for $X$. 
(1) De man heeft op de boot gewacht.

the man has on the boat waited

'The man waited for/on the boat.'

It is commonly assumed that syntactic structures are built incrementally, on a word-by-word basis (e.g. Marslen-Wilson 1973; Phillips 2003). On this assumption, however, head-final constructions like (1) are problematic: the argument status of the PP is not determined until the sentence-final verb comes in. These preverbal PPs are therefore locally ambiguous between attachment as argument and as adjunct.

This study addresses the question how these PPs are incrementally attached to the unfolding structural representation of the sentence, and how this structure is revised when the attachment that is selected turns out to be incorrect. We present data from a self-paced reading task with native speakers of Dutch. Our results suggest that there is an overall preference for adjunct attachment. This finding contrasts with the commonly held view in psycholinguistics that parsers aim to build the simplest structure possible, and thereby casts doubts on the rigid application of such parsing principles.

\section{Theoretical background}

The Garden-Path model was one of the earliest models of sentence processing that attempted to account for the incremental interpretation of ambiguous sentences using structural principles (Frazier 1987; Frazier \& Fodor 1978). In this serial model, initial parsing decisions are based on two principles: Minimal Attachment (attach an incoming phrase using the least structure possible) and Late Closure (attach an incoming phrase to the phrase most recently postulated). This model captured a wide range of attachment preferences in structurally ambiguous sentences, with the VP-attachment preference in sentences like The spy saw the cop with the binoculars as a prime example (Rayner et al. 1983).

Frazier's seminal work sparked a large number of experimental attempts to test this model, which revealed, among others, that attachment preferences can be biased by lexical information such as a verb's argument structure. A now wellestablished result in psycholinguistics is that arguments are easier to process than adjuncts. For instance, after The local florist delivers flowers ..., the argument PP to my church is read faster than the adjunct PP to my delight (Speer \& Clifton 1998; Shapiro et al. 1993). Argument attachment is also preferred for PPs that are ambiguous between argument and adjunct in V-NP-PP sequences. The NPmodifying argument for a raise, for example, is read faster than the VP-modifying 
adjunct for a month when preceded by The company lawyers considered employee demands... (Abney 1989; Boland \& Blodgett 2006; Schütze \& Gibson 1999). To explain this 'argument advantage', newer parsing models assumed a more strongly lexicalized representation of grammatical knowledge. Such 'head-driven parsing models' place emphasis on the presence of a lexical head as a necessary condition for the projection of phrase structure (Abney 1989; Pritchett 1992). The most recent version of the Garden-Path model, Construal Theory, restricts the application domain of Minimal Attachment and Late Closure to attachments that instantiate primary relations, including arguments (Frazier \& Clifton 1996). Nonprimary relations (i.e. adjuncts) are loosely 'associated' into the current thematic processing domain (i.e. the extended maximal projection of the last theta assigner). They initially receive an underspecified syntactic analysis, which is checked using both structural and non-structural (detailed lexical, pragmatic) knowledge.

Incremental models, such as Construal Theory, and head-driven models are well-equipped to deal with processing of arguments and adjuncts in a head-initial language like English, because the respective phrases are always preceded by a verbal head. Immediate activation of the verb's argument structure means that the number of arguments, as well as their specific thematic roles, can already be anticipated before the critical PP comes in. The argument advantage arises because the parser prefers to satisfy the verb's argument structure requirements at each point during the parse (Abney 1989; Pritchett 1992; Schütze \& Gibson 1999). However, these models lack explanatory power when it comes to the question how arguments and adjuncts are processed in head-final constructions in a language like Dutch, as the function of the relevant phrases becomes clear only after the clausefinal verb is processed. The conclusions one can draw about the universality of parsing mechanisms are therefore limited, because the proposed mechanisms do not make clear predictions for constructions that are not found in English. And, relatedly, parsing strategies might be modulated by the demands of the language under consideration, in that the relative contribution of certain well-established principles might be weighted by language-specific factors.

It is therefore important to investigate incremental comprehension of headfinal constructions as well, since they place very different computational demands on a parser (e.g. higher memory load), which potentially lead to differences in parsing strategy and/or capacity, and allow insight into attachment preferences in the absence of lexical (head) information. As a case in point, experiments on head-initial structures (in English, Russian) reveal so-called 'locality effects', i.e. increased processing costs for words that integrate longer dependencies (Gibson 1998; Levy et al. 2013). Studies that investigate head-final structures (in German, Hindi, Japanese), by contrast, report the exact opposite: the processing cost is 
decreased when dependencies are longer, an effect typically attributed to a stronger build-up of expectation (Konieczny, 2000; Husain et al. 2014). Vasishth et al. (2010) extend this idea by asserting that the parser adapts to specific grammatical properties of a particular language. They show that German speakers are hindered less than English speakers during the comprehension of sentences with multiple center embeddings, suggesting that German speakers' structural predictions for upcoming verbs are more robust.

These cross-linguistic differences might be related to the fact that the average dependency lengths in head-final languages are considerably longer than those in head-initial languages (Futrell et al. 2015). Speakers of head-final languages may thus be more practiced and therefore more skilled at processing longer dependencies. In light of these effects of a language's head-directionality on a speaker's processing capacity, the present study investigates how ambiguous preverbal PPs are processed in head-final constructions of Dutch.

\section{The present study}

We investigate attachment preferences for argument and adjunct PPs in Dutch verb-final constructions like (2). The grammatical function of these PPs is temporarily ambiguous between argument and adjunct, and this ambiguity is only resolved when the clause-final verb comes in. In particular, the PP op het dakterras 'on the roof.terrace' can be a prepositional argument to the verb bespaard 'saved', or, if the final verb is the intransitive gewerkt 'worked', a locative adjunct. Sentences like (2) are not easily accommodated by existing parsing theories, which, as pointed out above, are mainly based on head-initial English.

(2) De aannemer heeft op het dakterras bespaard/gewerkt. the contractor has on the roof.terrace saved/worked 'The contractor saved/worked on the roof terrace.'

In a self-paced reading paradigm, we presented participants with verb-final participle structures containing a PP, which is either an argument (3a) or an adjunct (3b). As Dutch allows PPs in postverbal position as well, we also included two conditions in which the order of verb and PP is inverted ( $3 c, 3 \mathrm{~d})$.

(3) a. De aannemer heeft $\left[_{\mathrm{PP}}\right.$ op het dakterras] bespaard nadat de cliënt the contractor has on the roof.terrace saved after the client instemde. agreed 
b. De aannemer heeft $\left[_{\mathrm{PP}}\right.$ op het dakterras] gewerkt nadat de cliënt the contractor has on the roof.terrace worked after the client instemde.

agreed

c. De aannemer heeft bespaard $\left[_{\mathrm{PP}}\right.$ op het dakterras] nadat de cliënt the contractor has saved on the roof.terrace after the client instemde.

agreed

d. De aannemer heeft gewerkt $\left[_{\mathrm{PP}}\right.$ op het dakterras $]$ nadat de cliënt the contractor has worked on the roof.terrace after the client instemde.

agreed

'The contractor saved/worked on the roof terrace after the client agreed.'

We adopt the traditional analysis that the Dutch VP is a head-final projection (Koster 1975), in which arguments are represented as sisters to the verbal head that selects them, while adjuncts are attached to a higher verbal projection (Chomsky 1981; Jackendoff 1977). The base order is the one in which the argument PP precedes the verb (PP-V). Postverbal argument PPs are derived by extraposition ('PP-over-V', Koster 1975), ${ }^{1}$ while adjuncts are generated in adjoined (nonargument) positions. The same procedure thus generates ( $3 b)$ and $(3 d)$, while (3c) is derived from (3a) by an extra movement operation.

Head-driven parsing models assume that phrase structure can only be projected after the lexical head has been processed, rendering preverbal PPs structurally uninterpretable until the clause-final verb comes in. However, assuming that comprehension of head-final constructions proceeds incrementally, and that the parser cannot entertain multiple structural continuations in parallel (Bader 2011; Konieczny 2000), the parser must choose a (temporary) attachment site for the PP in verb-final structures like (3a) and (3b). We consider two alternatives. Construal Theory favors argument attachment, because phrases that may or may not instantiate a primary relation are initially interpreted as primary phrases (Frazier \& Clifton 1996). If the PP is attached as an argument of a yet unpronounced verb, presentation of an intransitive verb should lead to reanalysis, as the PP must be relocated to an adjoined position. We hypothesize that reanalysis incurs processing difficulty and therefore increases reading times. Given that PPs are prototypically adjuncts rather than arguments, however, argument attachment will often turn out to be incorrect. We therefore consider a second option,

1. Classical evidence for extraposition is that extraction from postverbal PPs is not allowed (cf. Ross 1967): ${ }^{\star}$ Waar heeft de aannemer bespaard op_? vs. Waar heeft de aannemer op _ bespaard? 
in which adjunct attachment is actually favored for preverbal PPs. In this case, presentation of a transitive verb should lead to reanalysis, as the PP must be relocated to an argument position. We propose that adjunct-to-argument reanalysis is less costly than argument-to-adjunct reanalysis. This hypothesis is in line with the approaches of probabilistic parsing models, in which the parser considers a variety of information sources (e.g. argument structure, attachment frequency, complexity of reanalysis) to arrive at a syntactic analysis quickly, while minimizing processing cost (see Hale 2011 for discussion). Concerning V-PP orders, we expect to find an argument advantage, such that postverbal argument PPs are read faster than postverbal adjunct PPs. The next section reports a self-paced reading experiment in which we test our hypotheses.

\section{A self-paced reading experiment}

\subsection{Participants}

48 Dutch native speakers ( 38 female; ages $18-36$, mean age $=23.5$ ) participated in the experiment in exchange for a five euro gift card.

\subsection{Materials and design}

Our stimulus set consisted of 40 Dutch participle constructions with a PP, distributed over four conditions (see (3)). These were selected on the basis of a rating task $(n=45)$ with three argumenthood diagnostics. ${ }^{2}$ Argument and adjunct attachments were identical except for the verbs (transitive or intransitive), which were matched in terms of length and frequency $(t(38)=0.49, p=0.63$; frequencies were extracted from the SoNaR-corpus v1.2.1, Oostdijk et al. 2013). Each item ended with a four-word embedded clause that functioned as a spill-over region (see (3)). The experimental items were distributed over six lists, which also included the 48 fillers from the rating task. Every participant saw each item in only one condition. 25 items were followed by a yes-no comprehension question.

2. For a detailed discussion of the three diagnostics and the pretest, we refer the reader to the appendix, which can be found on our OSF page: https://osf.io/n8szb/. This repository also contains all supporting materials (i.e. stimuli, data, and analysis scripts). 


\subsection{Procedure}

Participants were individually tested in a sound-attenuated booth. They were instructed to read the sentences at their normal reading pace, and to answer the comprehension questions. Each trial started with a button press, after which the sentence was presented in a self-paced, word-by-word fashion, beginning from the left edge of the screen. The sentence outline was represented by a series of dots, which were replaced by words one at a time, as participants pressed a button. The experiment started with a practice session of four items, and was conducted using the Presentation software (Version 20.3)

\subsection{Analysis and results}

We measured reading times (RTs) for each word in the sentence. RTs exceeding $2000 \mathrm{~ms}$ were excluded (removing $0.5 \%$ of the trials), and all RTs were logtransformed to control for right-skewness of the data. For purposes of analysis only, we divided the data into three regions: the verb, the PP and the first three words of the spill-over region. We analyzed the average log RTs in these regions with linear mixed-effects models (Baayen et al. 2008), using the lme4 package (Bates et al. 2015) in R (version 3.6.1; R Core Team 2020). The factors attachment (argument, adjunct) and order (V-PP, PP-V) were entered into the model as fixed effects (deviation coded), together with their interaction. We added byparticipant and by-item random effects, each with random intercept and attachment as random slope.

The results of the experiment are presented in Figure 1. At the verb region, items with argument attachments (i.e. transitive verbs) were read more slowly than items with adjunct attachments (i.e. intransitive verbs) $(\beta=0.022, S E=0.008$, $t=2.60, p=0.01$ ), and verbs were read more slowly when they followed a PP (PP$\mathrm{V})$ than when they preceded one (V-PP) $(\beta=0.019, S E=0.008, t=2.33, p=0.02)$. The interaction between attachment and order was not significant $(\beta=0.005$, $S E=0.017, t=0.28, p=0.78)$. We subsequently analyzed the PP region in V-PP constructions only, since the sentences in PP-V are identical up to and including the PP. Argument and adjunct attachments in V-PP constructions elicited similar RTs $(\beta=0.003, S E=0.007, t=0.51, p=0.61)$. At the spill-over region, argument attachments were read more slowly than adjunct attachments $(\beta=0.015, S E=0.006$, $t=2.53, p=0.02$ ), and PP-V orders were read more slowly than V-PP orders $(\beta=0.012, S E=0.005, t=2.69, p=0.01)$. The interaction was not significant $(\beta=-0.005, S E=0.009, t=-0.55, p=0.58)$.

To control for a potential difference in predictability of clause-final verbs, we collected cloze probability values based on a non-speeded sentence-completion 
A.

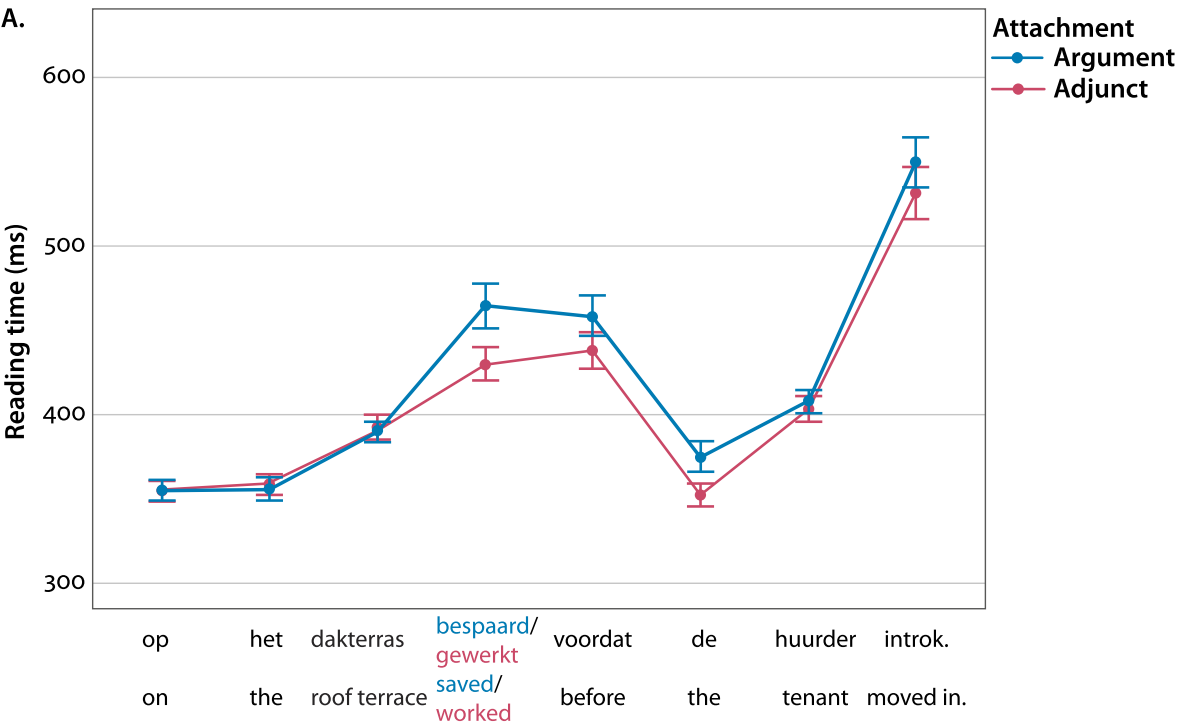

Region

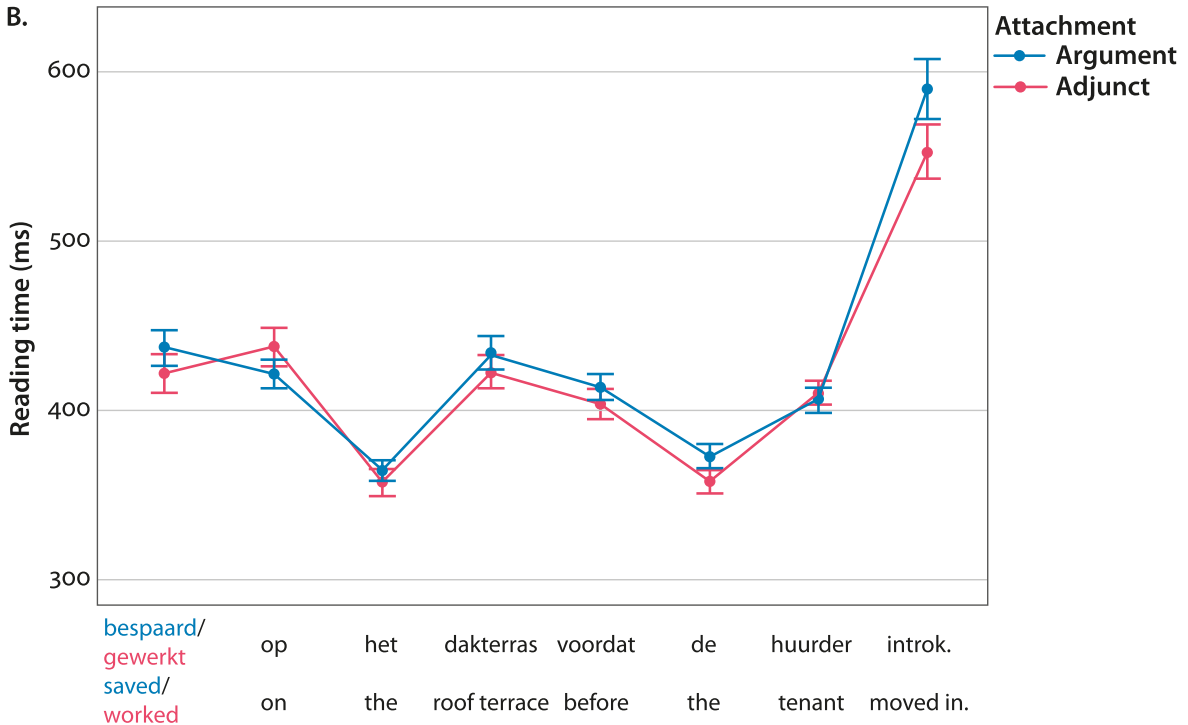

\section{Region}

Figure 1. Reading times per word in PP-V constructions (A) and V-PP constructions (B). Error bars reflect within-subjects standard error of the mean. 
task with an additional group of 41 Dutch participants (De aannemer heeft op het dakterras ...; see the appendix on our OSF page for a description). Sentences were more often completed with intransitive verbs than with transitive verbs $(\beta=0.074, S E=0.027, t=2.71, p=.01)$, indicating that intransitive verbs were more predictable. In order to check whether this difference in predictability was correlated with the RTs of the same clause-final verbs, we ran a mixed-effects analysis which included the factors attachment, each verb's cloze value, and the interaction between attachment and cloze. This revealed no effect of predictability on verb RT $(\beta=-0.207, S E=0.133, t=-1.56, p=0.12)$. Moreover, even when predictability was taken into account, clause-final transitive verbs were read more slowly than clause-final intransitive verbs $(\beta=0.026, S E=0.013, t=1.97, p=0.05)$. The interaction between predictability and attachment was not significant $(\beta=-0.384$, $S E=0.269, t=-1.43, p=0.15)$.

\section{Discussion}

Using a self-paced reading experiment we investigated incremental VPattachment of argument and adjunct PPs in Dutch. While we did not observe an argument advantage in postverbal PPs, we did find that transitive verbs, for which the PP is an argument, were read more slowly than intransitive verbs, for which the $\mathrm{PP}$ is an adjunct.

\subsection{No argument advantage for postverbal PPs}

Psycholinguistic studies with head-initial constructions strongly suggest that arguments are easier to process than adjuncts (i.e. 'argument advantage'), because they can be anticipated based on the preceding lexical head (Boland \& Blodgett 2006; Schütze \& Gibson 1999; Shapiro et al. 1993; Speer \& Clifton 1998). We did not replicate this finding in our experiment; the RTs in constructions with a postverbal PP were strikingly similar. We will discuss several potential reasons for this unexpected null effect. First, it could be related to differences in the languages under consideration and/or (related) differences in the sentence materials. Previous studies looked at English verbs in the simple past, while we used Dutch verbs in the present perfect. We opted for this verbal form because the simple past is less commonly used in Dutch (cf. de Swart 2007), and because participle constructions allow for both preverbal and postverbal PPs. Notably, the postverbal PP constructions in our stimuli differed not only in attachment, but also in syntactic complexity. While the V-PP order for argument attachments is derived by extra- 
position of the PP (see (4); 'PP-over-V' in Koster 1975), adjunct PPs can be freely attached on the left or the right side of the phrase (Hunter \& Frank 2014).

(4)

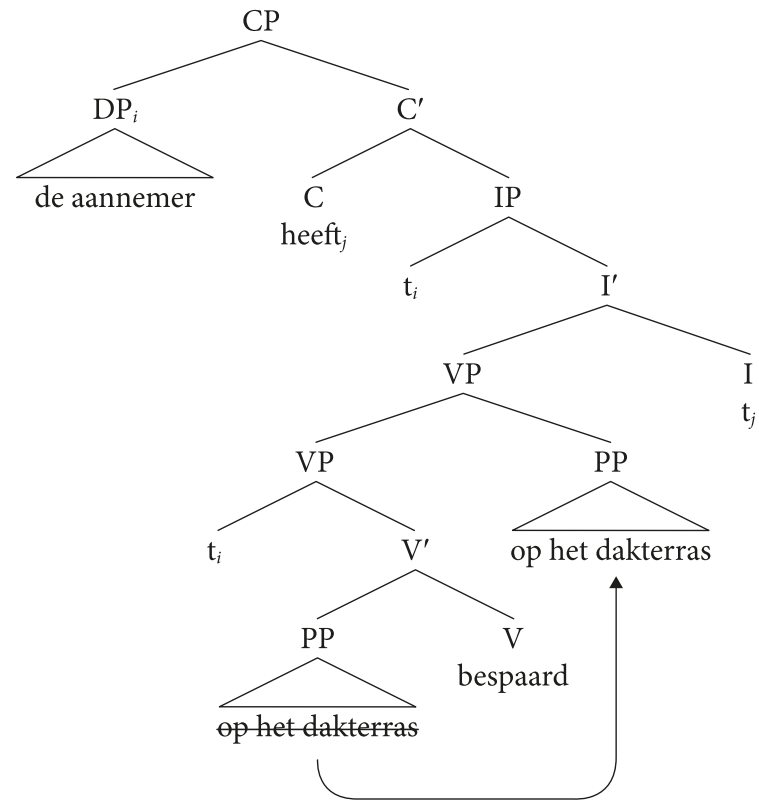

Thus, the postverbal position is a marked position for argument PPs, and might therefore be less frequent, following from a cross-linguistic preference to minimize dependency lengths (Futrell et al. 2015). The structural complexity of these structures in Dutch might counter the argument advantage that is often attested in English head-initial structures. Alternatively, it is possible that the argument advantage was in fact present (e.g. see RTs at $o p$ 'on' in Figure $1 \mathrm{~B}$ ), but that our selfpaced reading paradigm is not sufficiently sensitive to reveal this effect. Followup research is needed, for instance using eye-tracking, which provides a range of more sensitive measures (e.g. first pass reading time, regressions, skipping of highly predictable words), in order to study incremental attachment of argument/ adjunct PPs while controlling for the potential confounds just mentioned (e.g. using verb-second constructions in which the simple past is more natural: Tijdens de verbouwing bespaarde/werkte de aannemer op het dakterras 'During the renovation the contractor saved/worked on the roof terrace').

\subsection{A language-specific preference for adjunct attachment}

We found longer RTs for transitive than intransitive verbs, both in phrase-initial and phrase-final position. While the interaction between attachment and order was not significant, the numerical RT difference between transitive and intransitive verbs was twice as big in $\mathrm{PP}-\mathrm{V}$ constructions than in $\mathrm{V}-\mathrm{PP}$ constructions, and in the 
PP-V construction this effect spilled over into subsequent regions. We tentatively propose that participants preferred to attach preverbal PPs as adjuncts. Adjunct attachment in PP-V constructions is correct when the clause-final verb is intransitive, but incorrect when it is transitive. Presentation of a transitive verb triggers structural reanalysis, which incurs additional processing difficulty reflected here in increased RTs at the verb and subsequent regions.

An analysis in which preverbal PPs are initially attached as adjuncts finds support in a number of independent facts. For one, the preposition in argument PPs does not carry independent semantic content, but is lexically specified by the verb, see (5a). By contrast, adjunct PPs have a relatively constant semantic contribution to sentence, independent of the verb, see (5b).

(5) a. De aannemer heeft $\left[{ }_{\mathrm{PP}} \mathrm{op} /{ }^{*}\right.$ onder/ $/{ }^{*}$ naast het dakterras $]$ bespaard. the contractor has on/under/next.to the roof.terrace saved

b. De aannemer heeft $\left[_{\mathrm{PP}}\right.$ op/onder/naast het dakterras] gewerkt. the contractor has on/under/next.to the roof.terrace worked 'The contractor saved/worked on/under/next to the roof terrace.'

When the PP precedes the verb, its preposition can at that particular point only be interpreted semantically. For example, the preverbal PP op het dakterras is interpreted as 'on (top of)/at the roof terrace. This initial interpretation is falsified upon presentation of bespaard 'saved', and the locative interpretation of the preposition must be adjusted. Second, PPs are prototypically adjuncts rather than arguments, so in the case of structural ambiguity, adjunct attachment is most likely correct. Third, attaching the PP as an adjunct allows the parser to avoid complex reanalysis, because reanalyzing incorrectly attached adjuncts is theoretically less costly than reanalyzing incorrectly attached arguments. More specifically, when an adjunct $\mathrm{PP}$ has to be reanalyzed as an argument PP, it must be reattached as the VP-internal argument required by the (transitive) lexical verb, see (6).

(6)

Incremental structure building of VP: adjunct-to-argument reanalysis

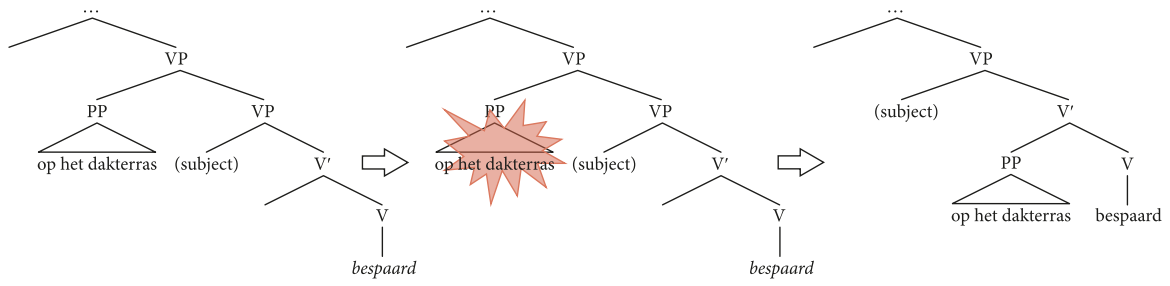

When an argument PP has to be reanalyzed as an adjunct PP, however, the initial argument position has to be destroyed to satisfy the (intransitive) verb's argument structure requirements, and a whole new position must be created to accommodate the adjunct. As a result, the entire VP has to be rebuilt, see (7). 
(7) Incremental structure building of VP: argument-to-adjunct reanalysis
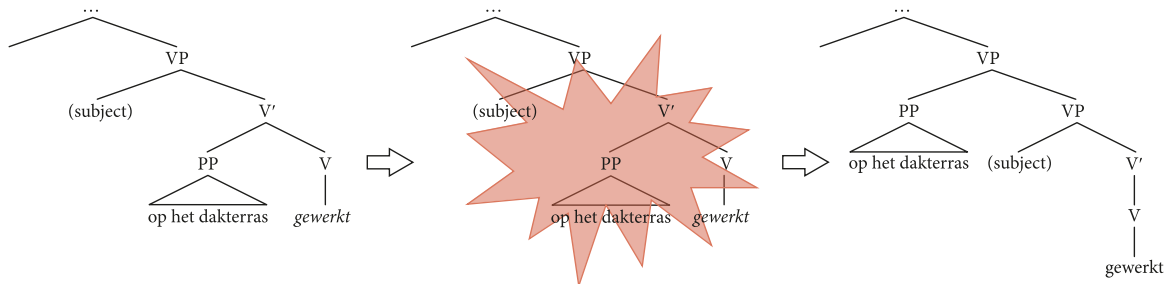

This analysis is reminiscent of the On-Line Locality Constraint proposed by Pritchett (1992), which also derives processing difficulty from the structural relationship between the initial and the final attachment site of locally ambiguous phrases. This constraint states that the final position of an ambiguous phrase must be in a configuration locally licensed by the source position (i.e. a form of government), otherwise attachment is impossible (i.e. leading to a gardenpath effect). On this account, the reanalysis in (6) is possible, because the initial (adjunct) position of the PP locally licenses the final (argument) position of the PP. The reanalysis in (7), however, does not meet this structural requirement, and is expected to lead to severe processing difficulty. We note that the proposal we lay out here is specific to the head-final constructions. As indicated, transitive verbs were read more slowly than intransitive verbs in general, including when they were located in phrase-initial position. We find this effect somewhat surprising, and think future research is required to examine whether it is specific to participle constructions or reflects the properties of transitive and intransitive verbs more generally.

In all, our proposal for head-final constructions illustrates how a parser could leverage both grammatical knowledge (in terms of the complexity-of-reanalysis alternatives) and probabilistic, language-specific knowledge (about which attachments are most common) of Dutch in the comprehension of head-final constructions. Its predictions contrast with a core principle of prominent parsing models. Specifically, the principle of Minimal Attachment dictates that parsers should avoid the postulation of potentially unnecessary material, such as intermediate projections that accommodate adjunct attachment (Frazier 1987; Frazier \& Clifton 1996). Our proposal downplays the determinism of such structural principles, instead suggesting that attachment preferences could be relativized and based on the frequency with which given phrases are arguments and adjuncts in a specific language. 


\section{Conclusion}

We presented reading-time data of arguments and adjuncts in Dutch verb-final constructions. Our findings show that there is no default preference for argument attachment in head-final processing, thus painting a picture that is more complex than has long been thought. We believe that future research should adopt a crosslinguistic approach in order to further specify how general parsing principles interact with language-specific structural knowledge, such as head-directionality, in order to achieve incremental comprehension of a diverse range of linguistic constructions.

\section{Acknowledgements}

We would like to thank Joske Piepers for her extensive help with the experiment. Our thanks also go out to the two reviewers, whose comments helped improve and clarify this manuscript.

\section{References}

Abney, Steven P. 1989. "A computational model of human parsing." Journal of Psycholinguistic Research 18 (1): 129-144. https://doi.org/10.1007/BF01069051

Baayen, R. Harald, Doug J. Davidson \& Douglas M. Bates. 2008. "Mixed-effects modeling with crossed random effects for subjects and items." Journal of Memory and Language 59 (4): 390-412. https://doi.org/10.1016/j.jml.2007.12.005

Bader, Markus. 2011. "On being both head-initial and head-final." Processing and producing head-final structures ed. by Hiroko Yamashita, Yuki Hirose and Jerome L. Packard. 325-348. London: Springer.

Bates, Douglas M., Martin Mächler, Benjamin M. Bolker \& Steven C. Walker. 2015. "Fitting linear mixed-effects models using lme4." Journal of Statistical Software 67 (1): 1-48. https://doi.org/10.18637/jss.v067.io1

Boland, Julie E. \& Austin Blodgett. 2006. “Argument status and PP-attachment." Journal of Psycholinguistic Research 35 (5): 385-403. https://doi.org/10.1007/s10936-006-9021-z

Chomsky, Noam. 1981. Lectures on government and binding: The Pisa lectures. Dordrecht: Foris.

Frazier, Lyn. 1987. "Sentence processing: A tutorial review." Attention and performance ed. by Max Coltheart. 559-586. Hiltsdale, NJ: Ertbauin.

Frazier, Lyn \& Charles Jr. Clifton. 1996. Construal. Cambridge, MA: MIT Press.

Frazier, Lyn \& Janet D. Fodor. 1978. "The sausage machine: A new two-stage parsing model." Cognition 6 (4), 291-325. https://doi.org/10.1016/0010-0277(78)90002-1

Futrell, Richard, Kyle Mahowald \& Edward Gibson. 2015. "Large-scale evidence of dependency length minimization in 37 languages." Proceedings of the National Academy of Sciences 112 (33), 10336-10341. https://doi.org/10.1073/pnas.1502134112 
Gibson, Edward. 1998. "Linguistic complexity: Locality of syntactic dependencies." Cognition 68: 1-76. https://doi.org/10.1016/Soo10-0277(98)00034-1

Hale, John T. 2011. "What a rational parser would do." Cognitive Science, 35 (3): 399-443. https://doi.org/10.1111/j.1551-6709.2010.01145.x

Hunter, Tim \& Robert Frank. 2014. "Eliminating rightward movement: Extraposition as flexible linearization of adjuncts." Linguistic Inquiry 45 (2): 227-267. https://doi.org/10.1162/LING_a_00154

Husain, Samar, Shravan Vasishth \& Narayanan Srinivasan. 2014. "Strong expectations cancel locality effects: Evidence from Hindi." PLOS ONE 9 (7): e100986. https://doi.org/10.1371/journal.pone.0100986

Jackendoff, Ray. 1977. X-bar syntax: A study of phrase structure. Cambridge, MA: MIT Press. Konieczny, Lars. 2000. "Locality and parsing complexity." Journal of Psycholinguistic Research 29 (6): 627-645. https://doi.org/10.1023/A:1026528912821

Koster, Jan. 1975. "Dutch as an SOV Language." Linguistic Analysis 1: 111-136.

Levy, Roger, Evelina Fedorenko \& Edward Gibson. 2013. "The syntactic complexity of Russian relative clauses." Journal of Memory and Language 69 (4): 461-495. https://doi.org/10.1016/j.jml.2012.10.005

Marslen-Wilson, William. 1973. "Linguistic structure and speech shadowing at very short latencies." Nature 244 (5417): 522. https://doi.org/10.1038/244522ao

Oostdijk, Nelleke, Martin Reynaert, Véronique Hoste \& Ineke Schuurman. 2013. “The construction of a 500-million-word reference corpus of contemporary written Dutch." Essential speech and language technology for Dutch: Results by the STEVIN-programme ed. by Peter Spyns and Jan Odijk. 219-247. London: Springer.

https://doi.org/10.1007/978-3-642-30910-6_13

Phillips, Colin. 2003. "Linear order and constituency." Linguistic Inquiry 34 (1): 37-90. https://doi.org/10.1162/002438903763255922

Pritchett, Bradley L. 1992. Grammatical competence and parsing performance. Chicago, IL: The University of Chicago Press.

R Core Team. 2020 R: A language and environment for statistical computing. R Foundation for Statistical Computing, Vienna, Austria.

Rayner, Keith, Marcia Carlson \& Lyn Frazier. 1983. "The interaction of syntax and semantics during sentence processing: Eye movements in the analysis of semantically biased sentences." Journal of Verbal Learning and Verbal Behavior 22 (3): 358-374. https://doi.org/10.1016/So022-5371(83)90236-o

Ross, John R. 1967. Constraints on variables in syntax. Doctoral dissertation, Massachusetts Institute of Technology.

Schütze, Carson T. \& Edward Gibson. 1999. “Argumenthood and English prepositional phrase attachment." Journal of Memory and Language 40 (3): 409-431. https://doi.org/10.1006/jmla.1998.2619

Schütze, Carson T. 1995. "PP Attachment and Argumenthood." MIT Working Papers in Linguistics 26: 95-151.

Shapiro, Lewis P., H. Nicholas Nagel \& Beth A. Levine. 1993. "Preferences for a verb's complements and their use in sentence processing." Journal of Memory and Language 31 (1): 96-114. https://doi.org/10.1006/jmla.1993.1006

Speer, Shari R., \& Charles Jr. Clifton. 1998. "Plausibility and argument structure in sentence comprehension.” Memory \& Cognition 26 (5): 965-978. https://doi.org/10.3758/BFo3201177 
Swart, Henriëtte de. 2007. “A cross-linguistic discourse analysis of the Perfect." Journal of Pragmatics 39 (12): 2273-2307. https://doi.org/10.1016/j.pragma.2006.11.006

Vasishth, Shravan, Katja Suckow, Richard L. Lewis \& Sabine Kern. 2010. “Short-term forgetting in sentence comprehension: Crosslinguistic evidence from verb-final structures." Language and Cognitive Processes 25 (4): 533-567.

https://doi.org/10.1080/01690960903310587

\section{Address for correspondence}

\section{Cas W. Coopmans}

Max Planck Institute for Psycholinguistics

Wundtlaan 1

6525 XD Nijmegen

The Netherlands

cas.coopmans@mpi.nl

\section{Co-author information}

Gert-Jan Schoenmakers

Centre for Language Studies

Radboud University

g.schoenmakers@let.ru.nl 